\title{
Asymmetric Lanthanum Doped Ceria Membrane with Proton Conductive and Hydrogen Separation Capability for Solid Oxide Fuel Cell
}

\author{
Warit Ua-amnueychai ${ }^{1, a}$, Keishi Asada ${ }^{2}$, and Katsunori Hanamura ${ }^{2, b}$ \\ 1 Department of Chemical Engineering, Graduate School of Science and Engineering, Tokyo Institute of \\ Technology, Tokyo, Japan \\ 2 Department of Mechanical and Control Engineering, Graduate School of Science and Engineering, Tokyo \\ Institute of Technology, Tokyo, Japan

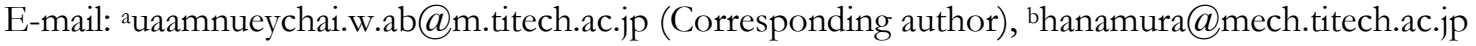

\begin{abstract}
An asymmetric lanthanum doped ceria (LDC) membrane was prepared by sintering process. The membrane consisted of two layers, dense LDC and porous Ni-LDC layers with a total thickness of approximately $850 \mu \mathrm{m}$. According to the XRD pattern, sintering process did not cause any chemical changes to the membrane. The membrane had a crystalline dense LDC layer with a highest hydrogen permeation flux of $1.3 \times 10^{-3}$ $\mathrm{mol} \cdot \mathrm{m}^{-2} \cdot \mathrm{s}^{-1}$, observed at a hydrogen partial pressure of $65.9 \mathrm{kPa}$ and operating temperature of $800^{\circ} \mathrm{C}$. The hydrogen permeation increased as the partial pressure of the hydrogen gas increased. The proton conducting permeation became more dominant as the hydrogen partial pressure decreased. The highest value was observed at $20.3 \mathrm{kPa}$ of hydrogen partial pressure, where $50.6 \%$ of the total permeation came from proton conducting ability of the membrane. While, the decreased in the operating temperature decreased the proton conductive permeation flux. With the decrease in the sintering temperature, the amount of pores in the dense LDC layer increased. The LDC membrane with both proton conductivity and hydrogen separation capability shows a promising potential as a hydrogen separation membrane and as a solid electrolyte for the solid oxide fuel cell.
\end{abstract}

Keywords: Lanthanum doped ceria, hydrogen separation, proton conducting, asymmetric membrane, solid oxide fuel cells.

ENGINEERING JOURNAL Volume 19 Issue 3

Received 27 May 2015

Accepted 27 May 2015

Published 5 June 2015

Online at http://www.engj.org/

DOI:10.4186/ej.2015.19.3.49 


\section{Introduction}

Rising of the environmental concerns, hydrogen energy, considered as a clean fuel, has been one of the most growing trend in this past decades. Solid oxide fuel cell (SOFC) is considered to be a promising high efficiency electrical energy conversion tool from hydrogen energy with low environmental impacts [1]. However, due to the expensive nature of the hydrogen production processes, it is of great concern to search for cost efficient hydrogen separation membrane in order to meet the demand of hydrogen gas. Many membranes are being studied to improve the efficiency of hydrogen separation. Some of those membranes are metallic, silica, zeolite, carbon-based and polymer membranes [2, 3]. However, with the application of solid oxide fuel cell, it is more advantageous for the hydrogen separation membrane to hold proton conductivity in order to be integrated as both hydrogen separation membrane and electrolyte for solid oxide fuel cell. In this case, the electrolyte can act as a hydrogen separation membrane to allow only hydrogen gas in the mixture of gases, such as industrial syngas or waste gasification [4], to pass through and also act as an electrolyte for the fuel cell to operate. This means simultaneous reaction and hydrogen separation can be made possible. Some of such membranes are mixed electron and proton conductive ceramic membranes such as $\mathrm{BaCeO}_{3}$ [5], $\mathrm{SrCeO}_{3}$ [6], $\mathrm{SrZrO}_{3}$ [7] and $\mathrm{BaZrO}_{3}$ [8]. Proton conducting solid electrolyte is generally used as a terms for such electrolytes.

Proton conducting solid electrolyte provides additional benefits when replacing the conventional type electrolytes. Generally, SOFC is based on the conduction of oxygen ions through the solid oxide electrolyte, which requires high operating temperature of over $1000^{\circ} \mathrm{C}$ [9]. However, the proton conducting electrolyte could allow the solid oxide fuel cell to be operated at much lower temperature, between 400 and $800^{\circ} \mathrm{C}$ [10]. The decrease in the operating temperature is one of the many advantage points of the proton conducting SOFC. This provides many benefits to the overall system; for example, lowering of operating cost, longer life time of equipment and shorter start-up time. Low activation energy [11] and high energy efficiency [12] add up the additional advantages of the proton conducting SOFC.

One promising materials that can be used as proton conducting solid electrolyte is the lanthanum doped ceria $\left(\mathrm{La}_{0.5} \mathrm{Ce}_{0.5} \mathrm{O}_{2-8}\right.$ or $\left.\mathrm{LDC}\right)$. $\mathrm{LDC}$ processes proton conductivity and hydrogen separation capability [13-15]. Moreover, LDC also shows significant stability in the presence of $\mathrm{CO}_{2}$ [16], which is the typical gas that mixed together with $\mathrm{H}_{2}$ from the industrial syngas. With these appreciable properties, LDC is a promising candidate as hydrogen separation membrane and electrolyte in solid oxide fuel cell [17]. Moreover, it is possible to improve the hydrogen permeance of the proton conducting membranes by altering the structure of the membrane. By preparing the membrane in an asymmetric manner, it is possible to reduce the thickness of membrane [18] and improve the permeability of hydrogen gas through the membrane [19]. The asymmetric structure is a bi-layer structure where the two layers of the membrane are dense layer and the thicker porous support. Both layers of the asymmetric membrane must made of the same proton conducting material.

This research focuses on the preparation of asymmetric LDC membrane with a total thickness of approximately $900 \mu \mathrm{m}$ by using conventional and cost-effective dry pressing/sintering process. This asymmetric membrane is a metal-ceramic composite membrane with a bi-layer structure consisting of a porous nickel-LDC layer and a dense LDC layer. The LDC asymmetric membrane was observed at different sintering temperature and heating and cooling rates used in the sintering process. The hydrogen permeability of this asymmetric membrane was also studied at various conditions, such as at different hydrogen partial pressure and operating temperatures. This could lead to better understanding of the LDC proton conducting membrane.

\section{Materials and Method}

\subsection{Membrane Preparation}

The lanthanum doped ceria (LDC) asymmetric membrane was prepared by dry pressing/sintering process. The asymmetric membrane consisted of two layers, porous substrate layer and dense LDC layer. The substrate mixture was prepared by mixing Nickel (II) Oxide (NiO, Kanto chemical Co., Inc), LDC (Kojundo Chemical Lab. Co., Ltd) and starch (Wako pure chemicals industries, Ltd.) powder with a mass ratio of 55:35:10 respectively. The mixture was dissolved in ethanol and stirred for 1 hour to ensure uniform mixing. After that, the mixture was dried in an oven for 1 hour at $80^{\circ} \mathrm{C}$. The porous substrate layer 
was fabricated by using a substrate powder with a mass of $0.8 \mathrm{~g}$ and co-pressed it in uniaxial direction at $100 \mathrm{MPa}$ into a disk shape having a diameter of $20 \mathrm{~mm}$. The LDC powder with a mass of $0.1 \mathrm{~g}$ was added on top of the co-pressed substrate layer. It was pressed again in uniaxial direction at $200 \mathrm{MPa}$. The sample was heated to the sintering temperature in an electric furnace with various heating rates, 5.0, 2.5 and 1.0 ${ }^{\circ} \mathrm{C} \cdot \mathrm{min}^{-1}$. Membrane was sintered for $5 \mathrm{~h}$ at various sintering temperature, 1400,1300 and $1200{ }^{\circ} \mathrm{C}$. After the sintering process, membrane was allowed to cool down to room temperature with different cooling rates of $5.0,2.5$ and $1.0{ }^{\circ} \mathrm{C} \cdot \mathrm{min}^{-1}$. The obtained membranes were used for further analysis.

\subsection{Analysis}

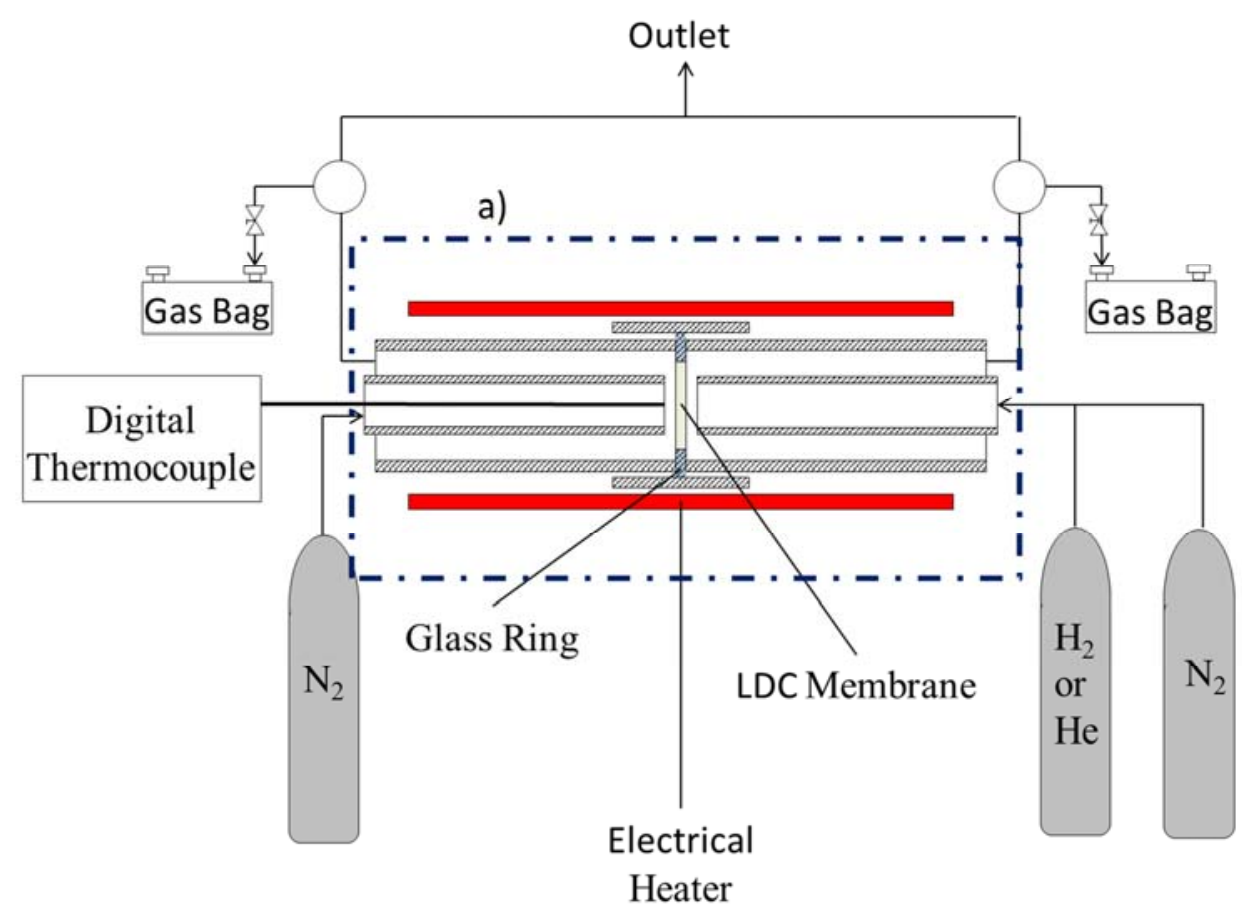

Fig. 1. Schematic of the hydrogen permeability test device.

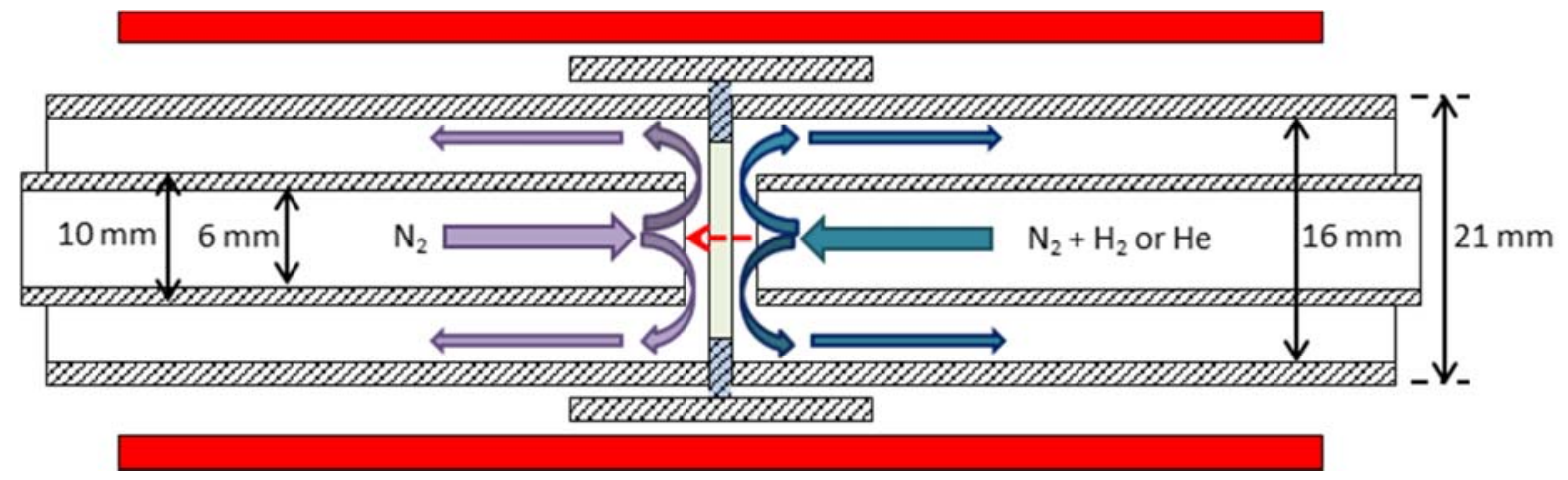

Fig. 1a). Dimensions and direction of gas flow for hydrogen permeability test device.

Surface and cross-section of the membranes were observed with scanning electron microscope (SEM, Hitachi miniscope TM-1000) to observe the porosity of the porous substrate layer, the thickness of the dense LDC layer as well as the porosity of the dense LDC layer. Moreover, X-ray diffraction (XRD, PANalytical X'Pert MPD) was used to analyze and compare between LDC powder and LDC layer of the sintered membrane. The comparison between the two is necessary to confirm that the sintering process, usage of high temperature, does not cause any chemical changes to the LDC structure. 
The hydrogen permeation of the membrane was measured using a self-made apparatus, which is shown in Fig. 1. The membrane was positioned and sealed between two ceramic tubes by glass rings. Electrical heater was used to heat up the system to $850^{\circ} \mathrm{C}$ to partially melt the glass ring and cooled down back to $800^{\circ} \mathrm{C}$, creating a complete sealing. The system was maintained at $800^{\circ} \mathrm{C}$ to measure the hydrogen permeability of the membrane. The porous side of the membrane was exposed to a mixture of $\mathrm{H}_{2}$ and $\mathrm{N}_{2}$ as shown in Fig 1a), which is called the "fuel side". By changing the flow rate of the hydrogen gas, the partial pressure of hydrogen gas at the fuel side was varied, 20.3, 35.5, 50.7, 60.8 and $65.9 \mathrm{kPa}$. On the other side of the device, refer as a "sweeping side", the dense LDC layer was exposed to only nitrogen gas with a fixed flow rate of $100 \mathrm{~mL} \cdot \mathrm{min}^{-1}$. The components of the permeated gas were collected by gas bag and were measured by gas chromatography (Shimazdu GC-8A). The permeation flux $\left[\mathrm{mol} \cdot \mathrm{m}^{2} \cdot \mathrm{s}^{-1}\right]$ was calculated by using the following equations.

$$
\text { Permeation flux }=\frac{N_{\mathrm{H}_{2}}}{A \cdot 60}
$$

where $N_{H_{2}}$ is the amount of hydrogen gas measure by GC $\left[\mathrm{mol} \cdot \mathrm{min}^{-1}\right]$ and $A$ is the total area of the membrane available for hydrogen gas to permeate through $\left[\mathrm{m}^{2}\right]$. The experiment was repeated with different operating temperatures of 750 and $700^{\circ} \mathrm{C}$.

Apart from hydrogen gas, helium gas was also used to replace hydrogen gas in another set of experiments to be fed into the system at the fuel side with different helium partial pressures, 20.3, 35.5 and $50.7 \mathrm{kPa}$. Due to the limitation of the equipment used, it is not possible to raise the helium partial pressure higher than $50.7 \mathrm{kPa}$. The measurement of the helium permeability is to observe the permeation of hydrogen gas by physical diffusion as both gases, hydrogen and helium, have very similar diffusion coefficient, thus very similar rate of physical diffusion [20]. The result will be used to differentiate between physical permeation and proton conducting ability of the membrane. This will be a new, simple and faster method to measure the proton permeability of the membrane. The hydrogen gas permeation, in principle, should be higher than that of helium gas due to the addition from proton conducting. Therefore, the different between the total permeation flux of the hydrogen gas and helium gas can be approximated to be equal to the permeation flux of hydrogen gas by proton conducting of the membrane.

\section{Results and Discussion}

\subsection{Effects of Heating and Cooling Rates}

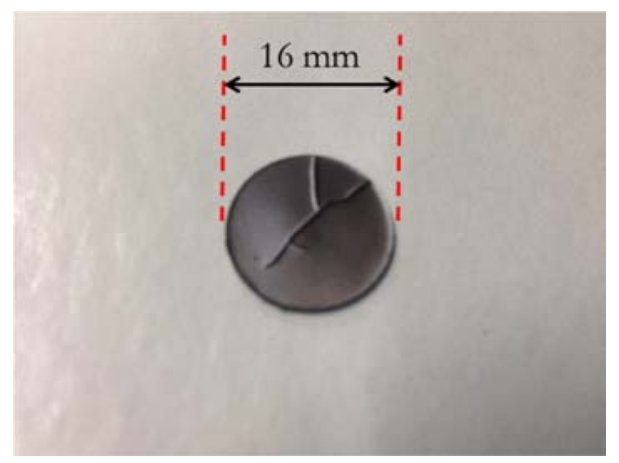

Fig. 2. Image of membrane sintered at $1400^{\circ} \mathrm{C}$ for $5 \mathrm{~h}$ at heating and cooling rates of $5.0^{\circ} \mathrm{C} \cdot \mathrm{min}^{-1}$.

The sintered membrane shrink in side to about $16 \mathrm{~mm}$ in diameter, due to the fusing of particles. The sintered membrane at the heating and cooling rates of $5.0^{\circ} \mathrm{C}$ was observed to have a crack. The crack occurred only in the dense LDC membrane, while the porous substrate layer remained intact as shown in Fig 2. This is because, in the porous layer, there was enough free space for the particle to shrink and expand. However, at the dense layer, the LDC powder underwent sintering process, where atoms in the powder particles diffused across the boundaries and fused together. The fusing of the particles allowed the elimination of small pores and caused shrinkage in the piece and resulted in a solid piece. Thus, it can lead to a formation of cracks. 


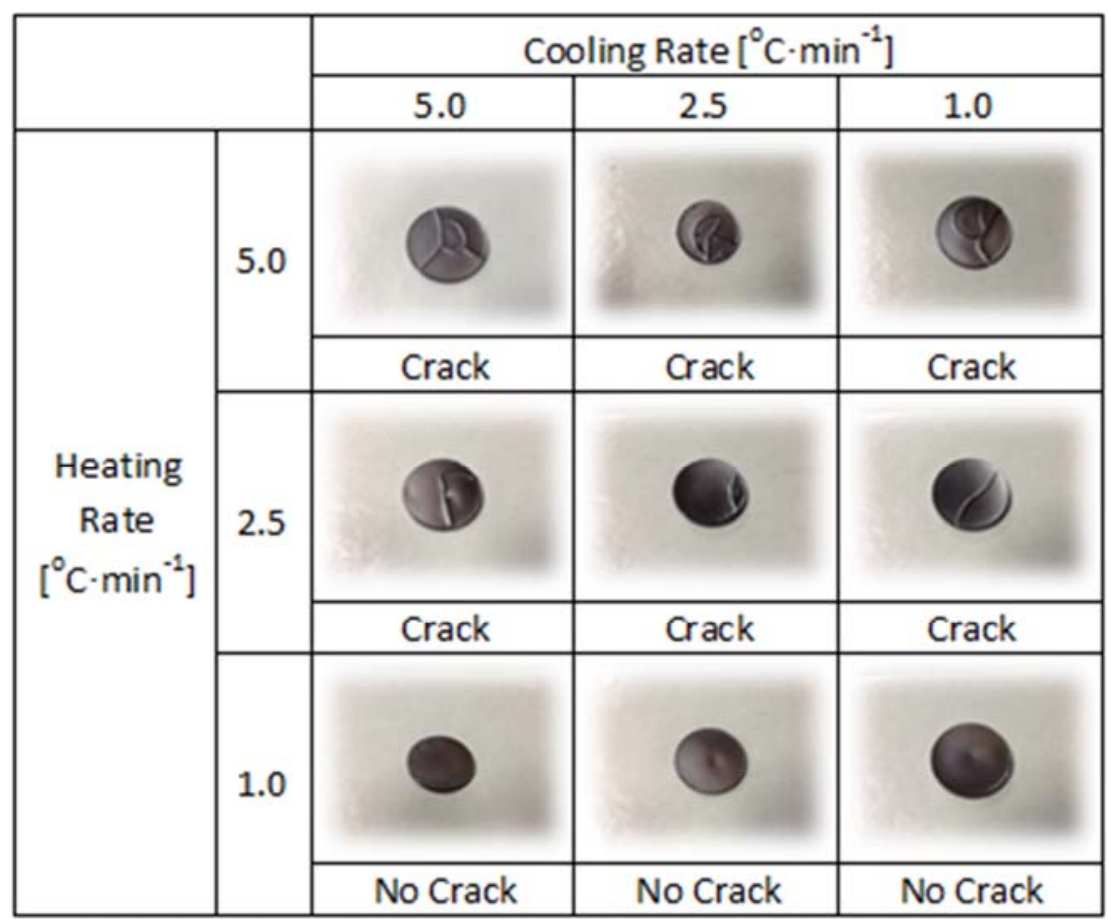

Fig. 3. Images of membrane prepared by sintering process at $1400^{\circ} \mathrm{C}$ for $5 \mathrm{~h}$ with different heating and cooling rates.

In order to try eliminate the crack in the dense LDC layer, two approaches were taken. The two approaches are decreasing of the cooling rate and decreasing of the heating rate used in the sintering process. Fig. 3 shows all the result of the sintered LDC asymmetric membrane with different heating and cooling rates $\left(5.0,2.5\right.$ and $\left.1.0^{\circ} \mathrm{C} \cdot \mathrm{min}^{-1}\right)$ at a fixed sintering temperature of $1400^{\circ} \mathrm{C}$ for 5 hours.

For the first approach, the cooling rate used to prepared the LDC asymmetric membrane was decreased to 2.5 and $1.0{ }^{\circ} \mathrm{C} \cdot \mathrm{min}^{-1}$. However, cracks were still observed in the dense LDC layer of the asymmetric membrane as shown in Fig 3. The decrease in the cooling rate means that the effect of thermal expansion, or in this case the shrinkage of the membrane during the cooling down of the samples was minimized, but since the membrane is a ceramic based membrane, usually relatively small thermal expansion. Thus, this can be concluded that the crack did not occur during the cooling down of the sintered membrane and therefore decreasing the cooling rate does not produce any result in elimination of the crack formation.

Another approach, decreasing the heating rate in the sintering process, did not produce positive result when decreasing the heating rate from 5.0 to $2.5^{\circ} \mathrm{C} \cdot \mathrm{min}^{-1}$ as cracks can still be observed in the dense LDC layer on the membrane samples as shown in Fig 3. However, the positive results was obtained when decreasing the heating rate further to $1.0{ }^{\circ} \mathrm{C} \cdot \mathrm{min}^{-1}$. Both dense LDC and porous layer remained intact without any cracks being observed on the membrane as shown in Fig 3. At high heating rate, cracks were formed mainly due to two possible reasons. First, at high heating rate, the fusing process of the particles is more rapid and this leads to a severe shrinkage of the dense LDC layer and results in high internal stress. This leads to a formation of cracks. Another possible reason is that high heating rate causes the outer region of the sample to be at higher temperature, while the inner region remains at lower temperature. This causes a temperature profile with high temperature gradient in a radial direction. Due to the high temperature gradient, powders in the outer region, which are higher in temperature, undergo sintering process, while those in the inner region, low in temperature, remain in the powder form. This results in a non-uniform shrinkage and produces stresses, which leads to a formation of cracks. On the other hand, at lower heating rate, the shrinkage due to the sintering process is gentler, producing lesser internal stress. In addition, the temperature profile across the sample is more uniformly distributed. This allows both, outer and inner regions to have similar temperature and results in a uniform shrinkage of the sample which avoids cracking in the dense LDC layer. 


\subsection{Asymmetric LDC Membrane}

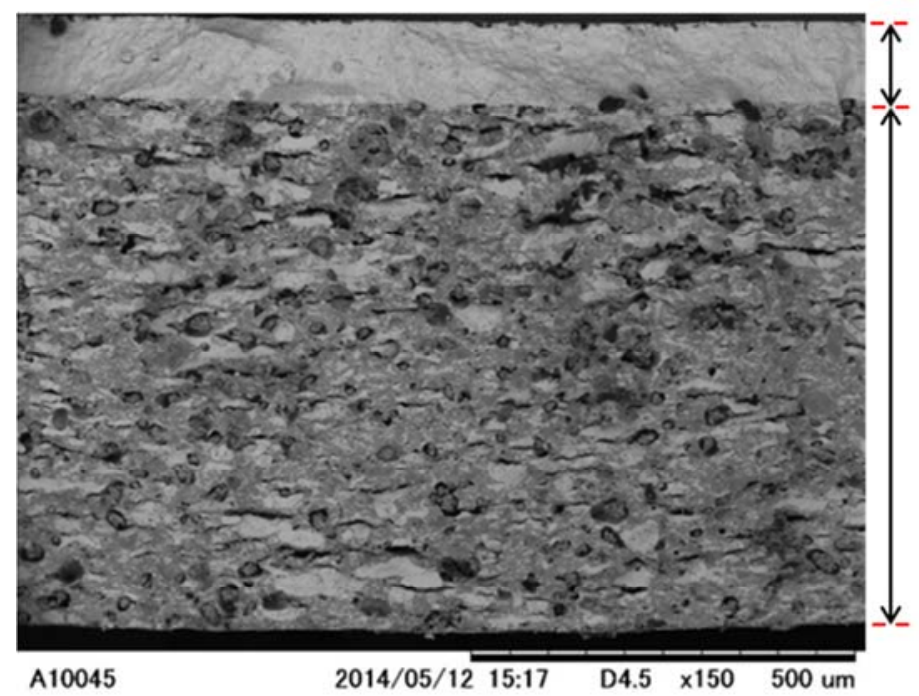

Dense LDC layer
Thickness $\approx 100 \mu \mathrm{m}$

Porous substrate layer

Thickness $\approx 750 \mu \mathrm{m}$

Fig. 4. Cross-sectional image of asymmetric membrane sintered at $1400^{\circ} \mathrm{C}$ with a heating rate of 1.0 ${ }^{\circ} \mathrm{C} \cdot \mathrm{min}^{-1}$ and a cooling rate of ${ }^{\circ} \mathrm{C} \cdot \mathrm{min}^{-1}$.

Figure 4 shows SEM image of the asymmetric membrane sintered at $1400^{\circ} \mathrm{C}$ at 150 times magnification. As expected, the image shows that the membrane clearly separated into two layers which are the dense LDC layer on top of the thicker porous substrate layer. According to the SEM image, the thickness was measured to be approximately 100 and $750 \mu \mathrm{m}$ for dense LDC and porous layer, respectively, having a total membrane thickness of approximately $850 \mu \mathrm{m}$. The total weight loss of the membrane after the sintering process is approximately $12.5 \%$, where about $8.9 \%$ are the mass loss due to the decomposition of starch in the porous substrate layer into gaseous compound. This is clearly reflect by the porous structure of the membrane in the porous substrate layer as observed in Fig. 4. The rest of the mass loss are probably due to the moisture content of the asymmetric membrane.

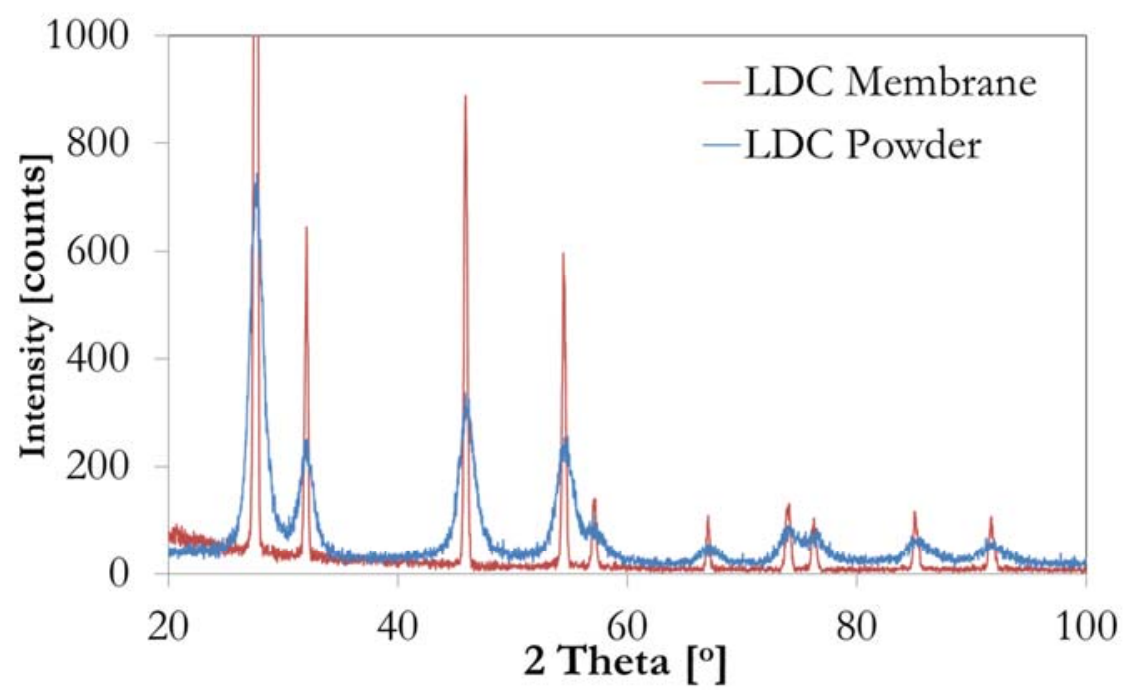

Fig. 5. XRD patterns of LDC powder and dense LDC layer of the asymmetric membrane sintered at $1400^{\circ} \mathrm{C}$ with a heating rate of $1.0^{\circ} \mathrm{C} \cdot \mathrm{min}^{-1}$ and a cooling rate of $5.0{ }^{\circ} \mathrm{C} \cdot \mathrm{min}^{-1}$.

Fig. 5 shows the XRD patterns of both LDC powder and LDC layer of the sintered asymmetric membrane. The purchased LDC powder was packed in a holding stand for analysis by XRD, while part of the LDC layer of the membrane was used for analysis by XRD. They both had very similar pattern with no 
obvious chemical changes to the structure of the LDC after sintering process. This confirmed that the sintering process, usage of high temperature, did not cause any chemical changes to the LDC. In addition, according to XRD pattern of the LDC membrane, the peaks were much sharper, which indicates that the structure of the LDC in the sintered membrane contained high crystallinity.

\subsection{Effects of Nickel(II) Oxide Reduction}

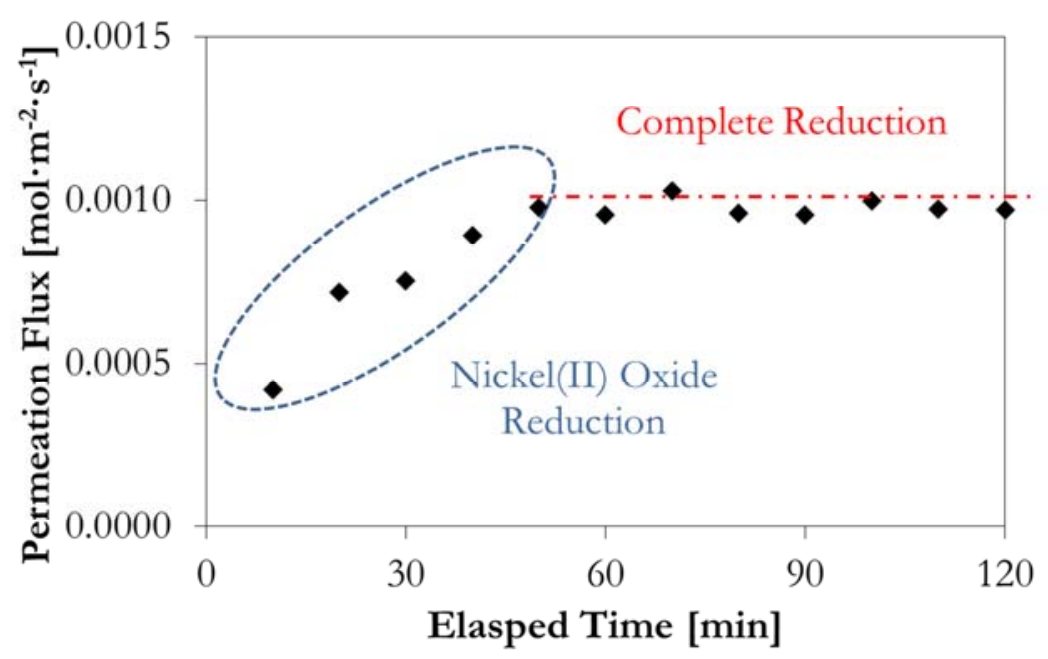

Fig. 6. Effect of nickel (II) oxide reduction on hydrogen permeability of the membrane as a function of operating time.
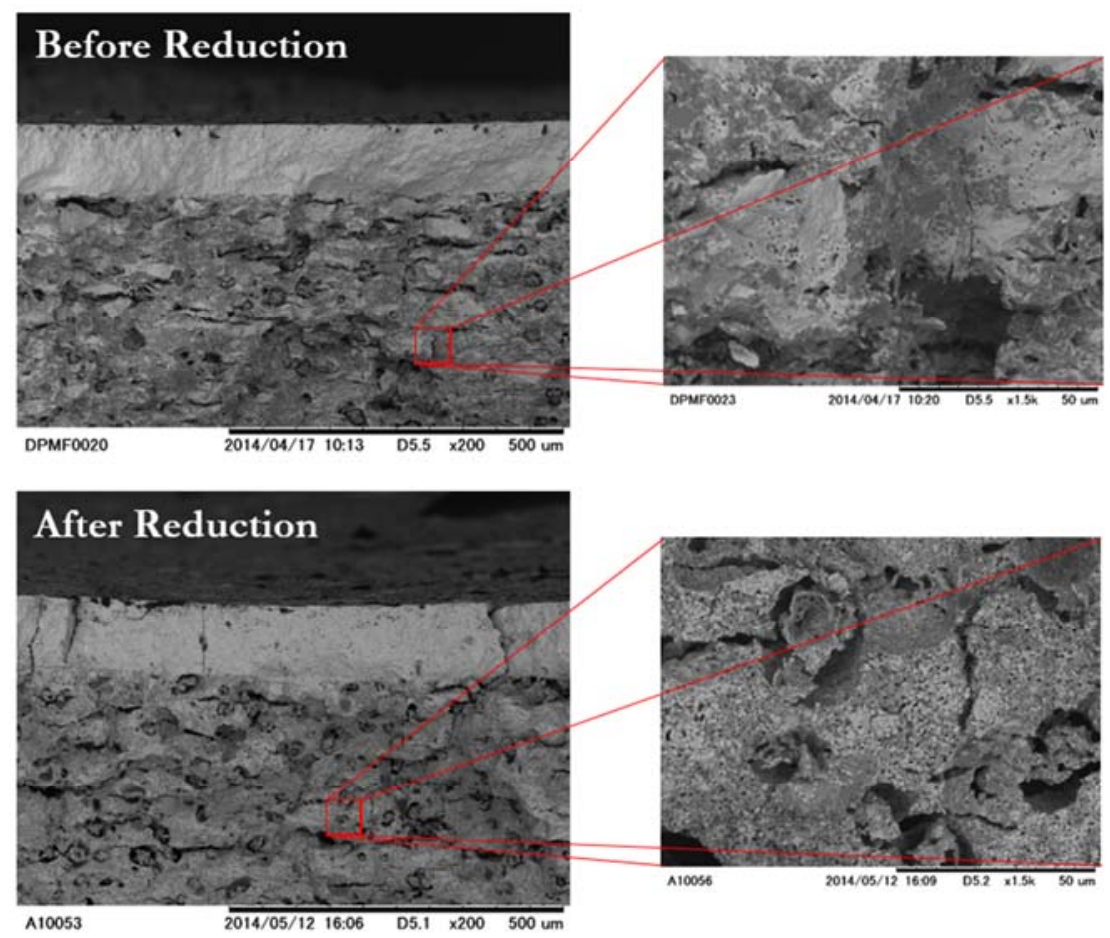

Fig. 7. Cross-sectional images of asymmetric LDC membrane sintered at $1400^{\circ} \mathrm{C}$ with a heating rate of 1.0 ${ }^{\circ} \mathrm{C} \cdot \mathrm{min}^{-1}$ and a cooling rate of $5.0^{\circ} \mathrm{C} \cdot \mathrm{min}^{-1}$ before and after nickel (II) oxide reduction.

LDC asymmetric membrane underwent reduction reaction to remove oxygen from nickel (II) oxide. This increased the porosity of the porous layer of the membrane, which increased the total hydrogen permeability through the membrane. The reduction reaction was done by heating the membrane to $800^{\circ} \mathrm{C}$ 
in a hydrogen rich environment, in this case, a gas mixture of hydrogen and nitrogen with a total flow rate of $200 \mathrm{~mL} \cdot \mathrm{min}^{-1}$ and $50 \%$ hydrogen concentration. Permeation flux of hydrogen as a function of time is shown in Fig. 6. As expected, hydrogen permeation flux increased as the time passed by, this is because the oxygen in the nickel (II) oxide was reduced by hydrogen gas leaving small pore in the porous substrate layer. This resulted in an increasing porosity in the porous substrate layer, which allowed more hydrogen gas to pass through the asymmetric membrane by physical diffusion mechanism. After $60 \mathrm{~min}$, the permeation flux became stable at a value of $9.7 \times 10^{-4} \mathrm{~mol} \cdot \mathrm{m}^{-2} \cdot \mathrm{s}^{-1}$. This showed that at least 60 minutes of nickel (II) oxide reduction time was necessary to complete the reduction process and allowed the system to become steady.

Moreover, with further analysis by SEM, it confirmed that after nickel (II) oxide reduction process the porosity of the membrane was increased as shown in Fig. 7. This is in agreement with the previous result as the permeation flux of hydrogen increased as the oxygen was reduced due to the increase in the porosity of the membrane. The pores were observed to have a size of less than $1 \mu \mathrm{m}$. Moreover, as expected, the reduction of the nickel (II) oxide process did not affect the structure of the dense LDC layer.

\subsection{Effects of Hydrogen Partial Pressure on Hydrogen Permeation Flux}

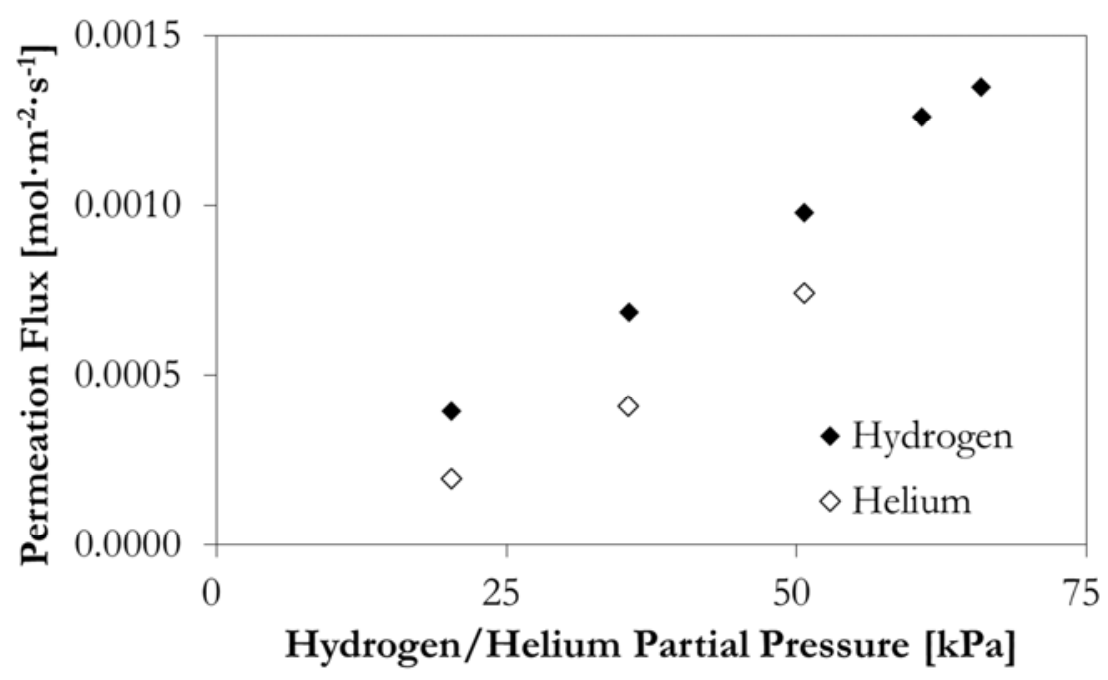

Fig. 8. Permeation flux at 10 min of operating time for a membrane sintered at $1400^{\circ} \mathrm{C}$ with a heating rate of $1.0{ }^{\circ} \mathrm{C} \cdot \mathrm{min}^{-1}$ and a cooling rate of $5.0{ }^{\circ} \mathrm{C} \cdot \mathrm{min}^{-1}$ as a function of hydrogen or helium partial pressure at operating temperature of $800^{\circ} \mathrm{C}$.

Both hydrogen and helium permeation flux were measured to investigate the effect of the hydrogen concentration on the fuel side. In this case, the proton conductive LDC asymmetric membrane allows hydrogen gas to permeate through by two mechanisms. The first is the physical permeation through the pores in the asymmetric membrane, while another mechanism is the permeation by proton conducting property of the membrane. For the physical permeation, it is due to the diffusion of the gaseous species in accordance to Flick's law. However, the permeation by proton conducting mechanism is much more complicated, which involves many consecutive transfer processes. The transfer process starts when the gas phase hydrogen diffuse passes through the porous substrate layer and reaches the surface of the dense LDC layer in the fuel side (reaction site). Hydrogen adsorption, dissociation and charge transfer occurs at the membrane surface consecutively. $\mathrm{H}^{+}$diffuses in the bulk of the membrane, along and through the grain boundaries. $\mathrm{H}^{+}$reaches the other end of the membrane allowing proton reduction and hydrogen reassociation at the membrane surface on the sweeping side. Finally, hydrogen desorption occurs and hydrogen gas move away from the surface of the LDC asymmetric membrane $[17,21,22]$. However, in the case of helium gas permeation, it can only permeate through the asymmetric membrane by the physical diffusion through the pores according to Flick's law. As mentioned in the earlier section, the rate of physical diffusion of both hydrogen and helium gases are similar to each other. Therefore, the total permeation flux of the hydrogen gas subtracted by the total permeation flux of the helium gas would be the 
approximate value of the permeation flux of the hydrogen gas through the asymmetric membrane by proton conductivity.

The increase in the partial pressure of hydrogen in the fuel side resulted in an increased in the permeation flux of the hydrogen gas at the sweeping side as shown in Fig. 8. The permeation flux of hydrogen went up as high as $1.3 \times 10^{-3} \mathrm{~mol} \cdot \mathrm{m}^{-2} \cdot \mathrm{s}^{-1}$ at $65 \%$ hydrogen concentration, which was corresponded to hydrogen partial pressure of $65.9 \mathrm{kPa}$. In addition, when increasing the partial pressure of the helium gas, the permeation flux of helium gas also increase similar to the case of hydrogen gas. The increase in the permeation flux of both hydrogen and helium gases was due to the increase in partial pressure of the concerned gas in the system. This increased the diffusion gradient of the system and therefore, resulted in higher rate of physical permeation.

Moreover, as observed from Fig. 8, the total permeation flux of hydrogen is always greater than that of the helium gas. As mentioned earlier, this additional permeation flux is due to the permeation by proton conductive property of the membrane. The percentage of proton conductive permeation was calculated to increase $24.7 \%$ at partial pressure of $50.7 \mathrm{kPa}$ to 40.4 and $50.6 \%$ at partial pressure of 35.5 and $20.3 \mathrm{kPa}$, respectively. This is due to the large decrease in the physical permeation as the partial pressure decreased.

When comparing the obtained result to some of the previously studied results, Zhu et al. [14] and Fang et al. [16] had reported a hydrogen permeation flux of approximately $1.0 \times 10^{-4} \mathrm{~mol} \cdot \mathrm{m}^{-2 \cdot} \mathrm{s}^{-1}$ at a hydrogen partial pressure of $20.3 \mathrm{kPa}$ with $3 \mathrm{kPa}$ of $\mathrm{H}_{2} \mathrm{O}$ partial pressure, which is slightly lower than what we observed, $3.9 \times 10^{-4} \mathrm{~mol} \cdot \mathrm{m}^{-2} \cdot \mathrm{s}^{-1}$ at $20.3 \mathrm{kPa}$ of hydrogen partial pressure without $\mathrm{H}_{2} \mathrm{O}$. In addition, when comparing this novel asymmetric membrane to the usual hydrogen separation membrane, silica and palladium membrane shows approximately 10 and 100 times higher in hydrogen gas permeation, respectively [23, 24]. The highest value was observed by Khatib et al. [25] are $3.6 \times 10^{-2}$ and $2.5 \times 10^{-1}$ $\mathrm{mol} \cdot \mathrm{m}^{-2} \cdot \mathrm{s}^{-1}$ for silica and palladium membranes supported by porous alumina, respectively.

\subsection{Effects of Operating Temperature on Hydrogen Permeation Flux}

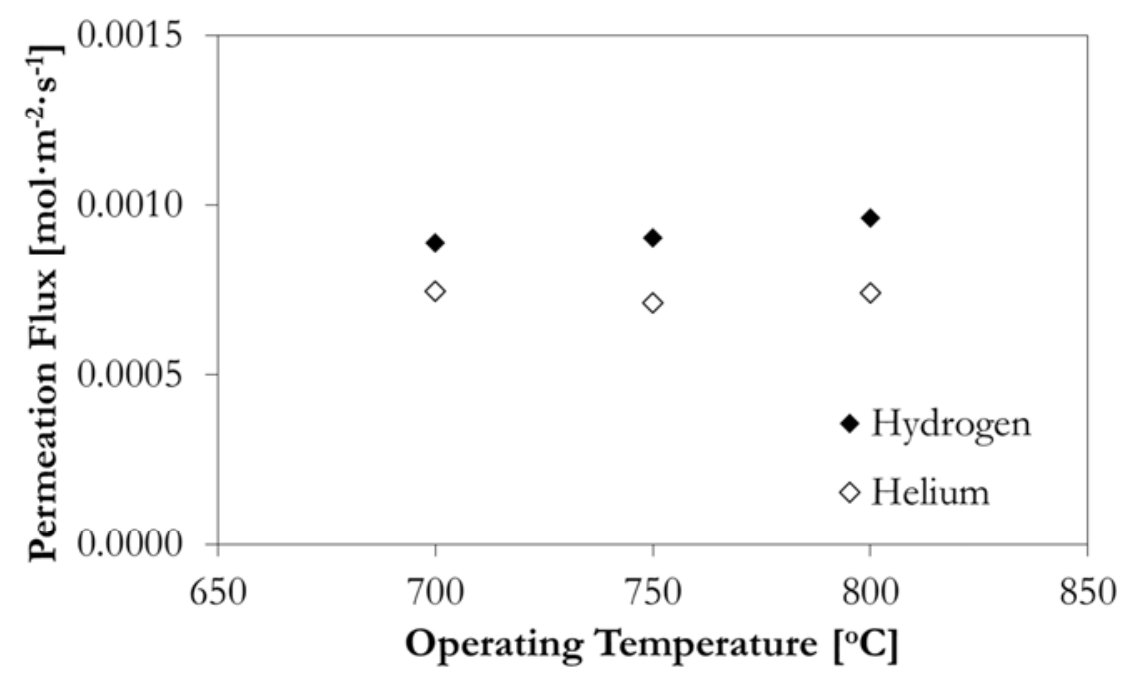

Fig. 9. Permeation flux at 10 min of operating time for a membrane sintered at $1400^{\circ} \mathrm{C}$ with a heating rate of $1.0{ }^{\circ} \mathrm{C} \cdot \mathrm{min}^{-1}$ and a cooling rate of $5.0{ }^{\circ} \mathrm{C} \cdot \mathrm{min}^{-1}$ as a function of operating temperature with hydrogen or helium partial pressure of $50.7 \mathrm{kPa}$.

When decreasing the operating temperature of the system, the hydrogen permeation flux also decreased slightly as shown in Fig. 9. Apart from the hydrogen permeation flux, the decrease in the operating temperature also decreased the helium permeation flux slightly. Moreover, when considering only the proton conductive permeation of hydrogen gas through the asymmetric membrane, Fig. 9 shows that as the operating temperature decreased, the proton conductive permeation also decreased. It decreased from a value of $2.2 \times 10^{-4} \mathrm{~mol} \cdot \mathrm{m}^{-2} \cdot \mathrm{s}^{-1}$ at an operating temperature of $800^{\circ} \mathrm{C}$ to a value of $1.9 \times 10^{-4}$ and $1.4 \times 10^{-4}$ $\mathrm{mol} \cdot \mathrm{m}^{-2 \cdot} \mathrm{s}^{-1}$ at the operating temperatures of 750 and $700^{\circ} \mathrm{C}$, respectively. As the operating temperature was decreased, the rate of hydrogen adsorption and dissociation at the surface of the dense LDC layer facing 
the fuel side could be slowed down, as a result, the rate of proton conductive permeation decreased. In addition to the adsorption and dissociation of hydrogen, hydrogen desorption rate at the opposing surface of the dense LDC layer can also possibly be affected by the decrease in the operating temperature. With all these factors in consideration, it shows that the operating temperature has a proportional relationship with the proton conductive permeation flux.

\subsection{Effects of Sintering Temperature}

Fig. 10 shows the SEM images of the LDC dense layer with 5000 times magnification for the membrane sintered at 1200,1300 and $1400^{\circ} \mathrm{C}$, respectively. The images show that sintering temperature had a large effect on the structure of the dense LDC layer. The membrane that was sintered at $1400^{\circ} \mathrm{C}$, Fig. 10c), showed the best structure among the 3 conditions experimented in terms of compact dense structure as well as crystalline structure. For the membrane sintered at $1400^{\circ} \mathrm{C}$, the dense LDC layer seemed to have a better uniform fusing throughout the piece. The uniform fusion between each LDC particles provided a truly dense LDC layer with very small amount of pores observed as shown in Fig 10. It also observed to have crystalline structure as suggested by a sharp peaks observed by XRD (Fig. 5). As the sintering temperature decreased, the fusion of the particles seemed to lose its uniformity and the porosity of the dense LDC layer increased. At high temperature, it allowed the LDC powder to have higher energy and diffused across the boundaries of the particles, thus fusing at a faster pace with the nearby particles. On the other hand, at lower temperature, the diffusion of the particles was slower and thus slower fusing between the LDC particles, therefore resulted in greater number of pores formed.

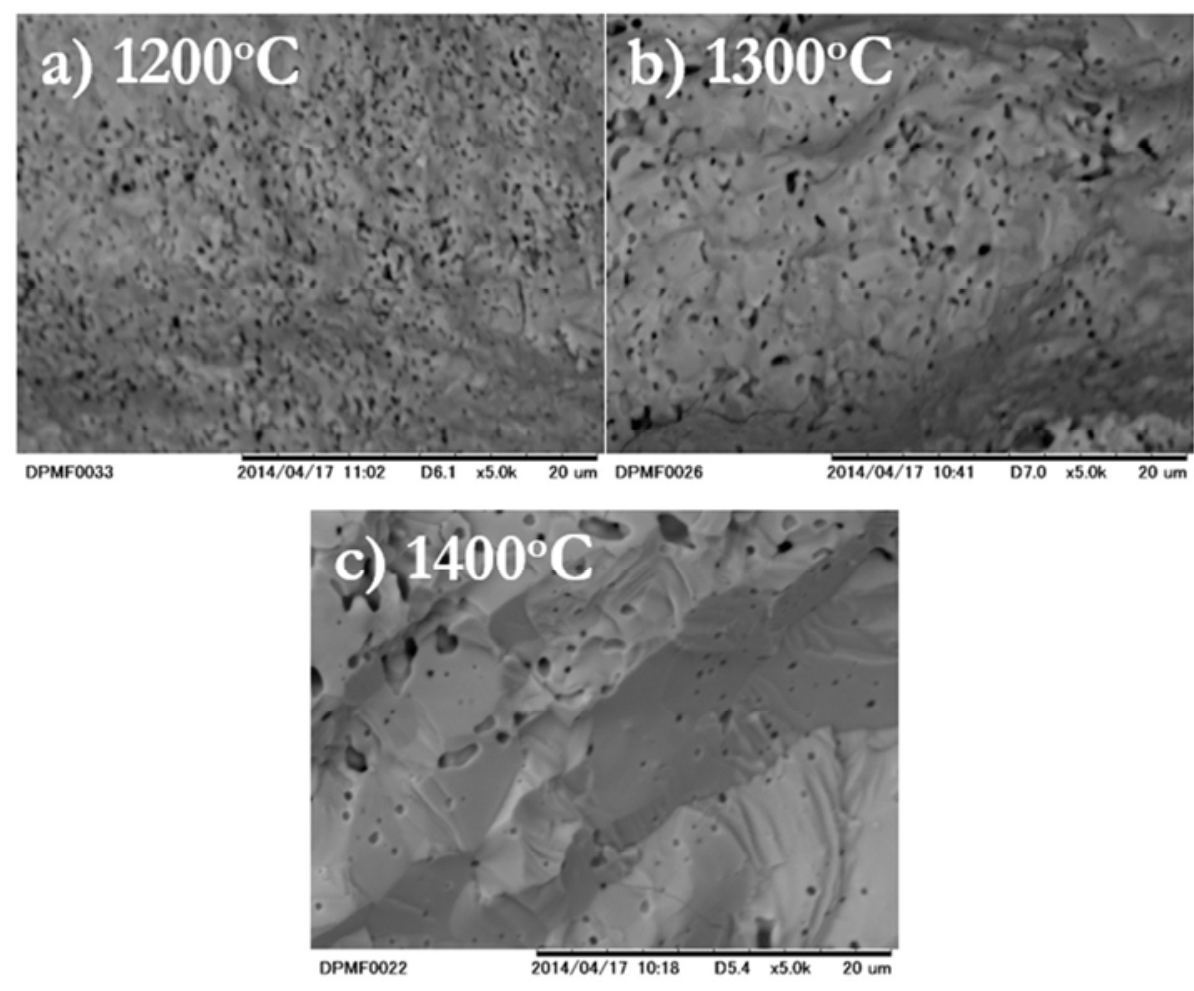

Fig. 10. SEM images of the LDC dense layer with a magnification of 5000 times for the membrane sintered with a heating rate of $1.0{ }^{\circ} \mathrm{C} \cdot \mathrm{min}^{-1}$ and a cooling rate of $5.0{ }^{\circ} \mathrm{C} \cdot \mathrm{min}^{-1}$ at sintering temperature of a) 1200 , b) 1300 and c) $1400^{\circ} \mathrm{C}$.

Due to the increase in the porosity, it is suspected that the overall hydrogen permeation would increase; however, the increase would mainly owe by the physical diffusion through the pores and not from the proton conducting ability of the membrane. In addition, even though, it is stated that the best condition observed is for the membrane with a sintering temperature of $1400^{\circ} \mathrm{C}$, some pores still observed in the dense LDC layer, which would allow certain amount of physical permeation to permeate through the membrane as discussed earlier and thus, unfavourable as a solid electrolyte for proton conducting fuel cell. 
From this result, it is believe that the pores can be further minimized by increasing the sintering temperature used in the sintering of the asymmetric membrane. This would probably decrease the amount of physical permeation of gases through the pores, hence increase the efficiency of the hydrogen gas separation and make it more favourable for application of solid oxide fuel cell.

\section{Conclusions}

The asymmetric LDC membrane with both proton conductivity and hydrogen separation ability shows a promising potential as a hydrogen separation membrane and as a solid electrolyte for the solid oxide fuel cell. The membrane sintered at $1400^{\circ} \mathrm{C}$ had a dense crystalline structure in the dense LDC layer with hydrogen permeation in the order of $10^{-3} \mathrm{~mol} \cdot \mathrm{m}^{-2} \cdot \mathrm{s}^{-1}$. By using the permeation of both hydrogen and helium gas, it could provide a clear differentiation between the physical permeation and proton conducting permeation of hydrogen gas through the LDC asymmetric membrane. Among the conditions tested, the highest percentage of proton conductive permeation was $50.6 \%$ at low hydrogen partial pressure of 20.3 $\mathrm{kPa}$. The increase in the hydrogen partial pressure in the fuel side resulted in the increase in the total gas permeation, mostly from the physical permeation. The decrease in the operating temperature showed a decrease in the proton conductive permeation, while decreasing the sintering temperature decreased the denseness of the LDC layer, which would allow more physical permeation through the pores.

\section{References}

[1] A. Choudhury, H. Chandra, and A. Arora, "Application of solid oxide fuel cell technology for power generation-A review," Renewable and Sustainable Energy Reviews, vol. 20, pp. 430-442, 2013.

[2] N. W. Ockwig, and T. M. Nenoff, "Membranes for hydrogen separation," Chemical Reviews, vol. 107, no. 10, pp. 4078-4110, 2007.

[3] D. Lee, and S. T. Oyama, "Gas permeation characteristics of a hydrogen selective supported silica membrane," Journal of membrane science, vol. 210, no. 2, pp. 291-306, 2002.

[4] F. Bellomare, and M. Rokni, "Integration of a municipal solid waste gasification plant with solid oxide fuel cell and gas turbine," Renewable Energy, vol. 55, pp. 490-500, 2013.

[5] H. Iwahara, T. Yajima, T. Hibino, and H. Ushida, "Performance of solid oxide fuel cell using proton and oxide ion mixed conductors based on $\mathrm{BaCe}_{1-\mathrm{x}} \mathrm{Sm}_{\mathrm{x}} \mathrm{O}_{3-\alpha}$," Journal of the Electrochemical Society, vol. 140, no. 6, pp. 1687-1691, 1993.

[6] H. Uchida, H. Yoshikawa, and H. Iwahara, "Dissolution of water vapor (or hydrogen) and proton conduction in $\mathrm{SrCeO}_{3}$-based oxides at high temperature," Solid State Ionics, vol. 35, no. 3, pp. 229-234, 1989.

[7] T. Yajima, H. Suzuki, T. Yogo, and H. Iwahara, "Protonic conduction in $\mathrm{SrZrO}_{3}$-based oxides," Solid State Ionics, vol. 51, no. 1, pp. 101-107, 1992.

[8] T. Shimura, K. Esaka, H. Matsumoto, and H. Iwahara, "Protonic conduction in Rh-doped $\mathrm{AZrO}_{3}$ (A= Ba, Sr and Ca)," Solid State Ionics, vol. 149, no. 3, pp. 237-246, 2002.

[9] K. Bae, D. Y. Jang, H. J. Jung, J. W. Kim, J. W. Son, and J. H. Shim, "Micro ceramic fuel cells with multilayered yttrium-doped barium cerate and zirconate thin film electrolytes," Journal of Power Sources, vol. 248, pp. 1163-1169, 2014.

[10] C. Solís, M. Balaguer, F. Bozza, N. Bonanos, and J. M. Serra, "Catalytic surface promotion of highly active $\mathrm{La}_{0.85} \mathrm{Sr}_{0.15} \mathrm{Cr}_{0.8} \mathrm{Ni}_{0.2} \mathrm{O}_{3-\delta}$ anodes for La ${ }_{5.6} \mathrm{WO}_{11.4-\delta}$ based proton conducting fuel cells," Applied Catalysis B: Environmental, vol. 147, pp. 203-207, 2014.

[11] A. F. Sammells, R. L. Cook, J. H. White, J. J. Osborne, and R. C. MacDuff, "Rational selection of advanced solid electrolytes for intermediate temperature fuel cells," Solid State Ionics, vol. 52, no. 1, pp. 111-123, 1992.

[12] A. K. Demin, P. E. Tsiakaras, V. A. Sobyanin, and S. Yu Hramova, "Thermodynamic analysis of a methane fed SOFC system based on a protonic conductor," Solid State Ionics, vol. 152, pp. 555-560, 2002.

[13] Z. Tao, L. Bi, S. Fang, and W. Liu, "A stable $\mathrm{La}_{1.95} \mathrm{Ca}_{0.05} \mathrm{Ce}_{2} \mathrm{O}_{7-\delta}$ as the electrolyte for intermediatetemperature solid," Journal of Power Sources, vol. 196, pp. 5840-5843, 2011. 
[14] Z. Zhu, L. Yan, H. Liu, W. Sun, Q. Zhang, and W. Liu, "A mixed electronic and protonic conducting hydrogen separation membrane with asymmetric structure," International Joumal of Hydrogen Energy, vol. 37, no. 17, pp. 12708-12713, 2012.

[15] L. Yan, W. Sun, L. Bi, S. Fang, Z. Tao, and W. Liu, "Effect of Sm-doping on the hydrogen permeation of $\mathrm{Ni}-\mathrm{La}_{2} \mathrm{Ce}_{2} \mathrm{O}_{7}$ mixed protonic-electronic conductor," International Journal of Hydrogen Energy, vol. 35, no. 10, pp. 4508-4511, 2010.

[16] S. Fang, L. Bi, L. Yan, W. Sun, C. Chen, and W. Liu, "CO 2 -resistant hydrogen permeation membranes based on doped ceria and nickel," The Journal of Physical Chemistry C, vol. 114, no. 24, pp. 10986-10991, 2010.

[17] Q. Zhang, X. Zheng, J. Jiang, and W. Liu, "Structural Stability of $\mathrm{La}_{2} \mathrm{Ce}_{2} \mathrm{O}_{7}$ as a Proton Conductor: A First-Principles Study," The Journal of Physical Chemistry C, vol. 117, no. 40, pp. 20379-20386, 2013.

[18] Z. Zhu, W. Sun, L. Yan, W. Liu, and W. Liu, "Synthesis and hydrogen permeation of Ni-Ba $\left(\mathrm{Zr}_{0.1} \mathrm{Ce}_{0.7} \mathrm{Y}_{0.2}\right) \mathrm{O}_{3-\delta}$ metal-ceramic asymmetric membranes," International Journal of Hydrogen Energy, vol. 36, no. 10, pp. 6337-6342, 2011.

[19] S. Cheng, V. K. Gupta, and J. Lin, "Synthesis and hydrogen permeation properties of asymmetric proton-conducting ceramic membranes," Solid State Ionics, vol. 176, no. 35, pp. 2653-2662, 2005.

[20] T. R. Marrero, and E. A. Maso, "Gaseous diffusion coefficients," Journal of Physical and Chemical Reference Data, vol. 1, no. 1, pp. 3-118, 1972.

[21] E. Kendrick, J. Kendrick, K. S. Knight, M. S. Islam, and P. R. Slater, "Cooperative mechanisms of fast-ion conduction in gallium-based oxides with tetrahedral moieties," Nature Materials, vol. 6, no. 11, pp. 871-875, 2007.

[22] J. W. Phair, and S. P. S. Badwal, "Review of proton conductors for hydrogen separation," Ionics, vol. 12, no. 2, pp. 103-115, 2006.

[23] M. Kanezashi, and M. Asaeda, "Hydrogen permeation characteristics and stability of Ni-doped silica membranes in steam at high temperature," Journal of Membrane Science, vol. 271, no. 1, pp. 86-93, 2006.

[24] W. H. Chen, and P. C. Hsu, "Hydrogen permeation measurements of Pd and $\mathrm{Pd}-\mathrm{Cu}$ membranes using dynamic pressure difference method," International Journal of Hydrogen Energy, vol. 36, no. 15, pp. 9355-9366, 2011.

[25] S. J. Khatib, and S. T. Oyama, "Silica membranes for hydrogen separation prepared by chemical vapor deposition (CVD)," Separation and Purification Technology, vol. 111, pp. 20-42, 2013. 